\title{
'It's a Mosher Just Been Banged for No Reason': Assessing Targeted Violence against Goths and the Parameters of Hate Crime
}

\author{
Jon Garland
}

\begin{abstract}
The murder of Sophie Lancaster in August 2007 in Lancashire, England, made national headlines, both for the brutal nature of the assault upon her and also because she had been attacked solely due to her 'alternative', gothic appearance. At the trial of her teenage assailants the judge surprisingly referred to the incident as a 'hate crime', apparently viewing the targeting of her 'difference' as being the key defining factor of what constitutes such a crime. This article will examine the validity of this assumption by analysing the characteristics of the assault upon Lancaster and also the nature, extent and impact of the harassment of goths and 'alternatives' more generally. It will assess the degree to which this type of victimisation is similar to that experienced by minority communities, such as gay, transgender, minority ethnic and disabled, who are routinely categorised, by both academics and practitioners, as being hate crime victim groups. The article will conclude that although there are inherent problems with classifying attacks upon goths as hate crimes, it may nonetheless be time to view the targeting of difference as being the most important aspect of what is, and is not, considered a hate crime.
\end{abstract}

Keywords: hate crime, goth subculture, victimisation, difference, targeted violence. 


\section{Introduction}

During the last ten years or so there have been a number of shocking cases of hate crime perpetration and victimisation in the United Kingdom that have helped to bring the issue to prominence. Whether it was the fatal assault upon Brent Martin, a man with mental health issues, in Sunderland in 2007, the homophobic murder of Jody Dobrowski in London in 2005 or the racist killing of black teenager Anthony Walker in Liverpool in the same year, violent hate crime has regularly featured in the news headlines in the first decade of the twenty-first century.

In many respects a similar case to these was the attack upon Sophie Lancaster in a small town in Lancashire, northern England in August 2007. Just as in the examples above, Lancaster was violently assaulted in a public place by a group of males who did not know her personally, and was beaten with such savagery that she lost her life. However, while the victims in the first three examples were targeted because of their membership of marginalised and (in the eyes of the assailants) despised minority outgroups, Lancaster was attacked for no other apparent reason than she stood out from the norm; she was 'different', and her startling appearance precipitated her victimisation. As Hodkinson suggests, 'Sophie Lancaster did not die because of her race, religion or sexuality. She died because she was a goth' (M. Hodkinson, 2008: 29). Her boyfriend, Robert Maltby, also a goth, was hospitalised in the same incident.

What makes this case especially intriguing for hate crime scholars is that while disabled, gay and minority ethnic communities are routinely viewed as hate crime victim groups and 
included under relevant legislation, goths or those belonging to 'alternative' subcultures ${ }^{1}$ are not. Interestingly, though, at the trial of Lancaster's attackers the presiding judge, Anthony Russell QC, made a point of labelling the murder a 'hate crime' (BBC News, 2008), apparently bracketing it with cases, like those of Martin, Dobrowski and Walker, that are clear-cut examples of the phenomena. The inference from Judge Russell's words is that, for a criminal incident to be considered a hate crime, the most important factor is that the victim was deliberately singled out because of their actual or perceived difference, even if this difference was due to their membership of a subcultural grouping rather than an 'established' minority hate crime victim group that has a history of marginalisation and discrimination (Perry, 2001). It is therefore felt that, by focusing upon the nature and experiences of goths and 'alternative' victims of targeted violence, the concept of hate crime itself can be examined and challenged.

This article will explore the implications of Judge Russell's statement by assessing whether the harassment and victimisation of goths or those who engage in 'alternative' subcultures has much in common with other forms of bias-motivated crimes that scholars and criminal justice agencies routinely categorise as hate crimes. It begins with a short discussion of the hate crime framework that provides the backdrop for the rest of the article and then details the history and multiple facets of the goth subculture itself. It then considers the Lancaster case at greater length as well as the harassment of, and violence against, goths more widely. Although there is a growing body of sociological work on gothic literature, films, fashions and music there is a dearth of criminological research on the victimisation of those in the subculture. The article draws upon the limited scholarly evidence that has been garnered thus far and complements this with analysis of news sources to provide a picture of the nature and extent of these incidents. Following this, the article draws parallels between this type of victimisation and that of other forms of recognised hate crime, such as the othering of 'despised' societal outgroups and the 'fear of difference' that may explain some of this harassment. The article concludes by suggesting that it may be time to develop an understanding of hate crime that includes victims who have been targeted because of their 
difference, whatever their background, rather than making hate crime victimisation solely the province of those from historically marginalised and disadvantaged communities.

\section{The Hate Crime Framework}

The use of the term 'hate crime' to describe the bias-motivated victimisation of minority groups has a more established history in the United States than it has in the United Kingdom. Its roots in the US are traceable to the civil rights struggles of various minority groups of four decades ago when it was used as a way of drawing out commonalities in the prejudice and victimisation faced by different marginalised communities (Grattet and Jenness, 2003). It gave such groups a banner to campaign under and also one that unified them in the common cause of challenging the types of ideologies that influenced hate-related harassment.

However, in the UK the concept of 'hate crime' has only gained widespread currency amongst academics and criminal justice practitioners in the last 10 years or so, precipitated in part by the bombing campaign of neo-Nazi David Copeland in London in 1999 that targeted the capital's minority ethnic and gay communities. Over successive weekends in April 1999 Copeland's nailbombs exploded in Brixton, Brick Lane and Soho, killing three people and injuring 129 (Hopkins and Hall, 2000). Copeland confessed that he had planted his bombs partly because he wanted them to act as a catalyst for a race war between Britain's white and minority ethnic communities, and partly because he simply hated gay people (McLagan and Lowles, 2000). His actions brought issues of prejudice and hatred against all minority groups very sharply into focus in a political and social climate that was already dominated by debates surrounding racism, diversity and discrimination following the publication of the Macpherson Report earlier that year (Rowe, 2007).

However, despite this growth in the employment of the hate crime concept it still remains both controversial and yet vague, as there is little agreement amongst academics or practitioners regarding what actually constitutes a 'hate crime' and which victim groups are actually hate crime victim groups. There is also much debate as to whether there are enough commonalities between the experiences of different hate crime victim groups for them all to 
be grouped together under the same 'hate crime’ banner (Bennett, Nolan and Conti, 2009). For authors like Gerstenfeld the key aspect of a hate crime is not that it is necessarily motivated by hatred towards the victim, but that the victim is targeted because of their actual or perceived membership of a social grouping that the perpetrator despises (Gerstenfeld, 2004). It is therefore who they are, rather than what level of bias, prejudice or hatred that was directed against them, that Gerstenfeld feels is most important in understanding the nature of hate crime.

Following on from this, another key aspect of the concept of hate crime is that different victims from the same background are, in theory, interchangeable with each other as it is not the individual characteristics of the victim that caused them to be singled out for harassment, but rather that they were a member of a despised and marginalised outgroup. Hate crimes are thus 'stranger danger' occurrences in which the perpetrator does not know the victim personally at all (Perry, 2001). Their purpose is to convey a powerful symbolic message to the victim and other members of their minority group that their presence is not welcome, with the underlying threat that further violence will be meted out upon any member of that group if they do not comply with the perpetrator's wishes (Saucier et al., 2006). Hate crimes therefore damage the self-worth, confidence and feelings of security of the victim more than 'ordinary' crimes as it is their intrinsic identity that is targeted: something which is central to their sense of being and which they cannot alter (Iganski, 2008).

For Perry (2009), the cultural, social and political processes that underline the perpetration of hate crime are important for understanding its broader structural elements. She views hate crime as being a symptom of society's inter-group conflicts in which the powerful commit acts of violence and intimidation upon the less powerful in order to maintain their privileged position. Such harassment reflects prevalent social attitudes and values that reproduce and maintain this inequality, as Perry (2009: 72) asserts:

... hate crime provides a context in which the perpetrator can reassert his or her hegemonic identity and, at the same time, punish the victim for the individual or 
collective performance of his or her identity. In other words, hate-motivated violence is used to sustain the privilege of the dominant group and to police the boundaries of the group by reminding the Other of his or her place. Perpetrators thus recreate their own masculinity, or whiteness, for example, while punishing the victims for their deviant identity performance.

Victims are thus members of socially and economically deprived minority groups who have historically been the subject of marginalisation and oppression. They lack access to political power and are subject to negative stereotyping which demeans their group. For Perry (2009: 60 ), this combination of 'structural exclusions and cultural imaging leave minority members vulnerable to systemic violence ... The former makes them vulnerable targets; the latter makes them "legitimate” targets.' This has important implications for the discussions of violence directed against goths as there is some debate as to whether a subcultural ‘community’ can fit Perry’s ideas of a hate crime victim group. This issue shall be returned to below.

Perry therefore offers a structural imagining of hate crime that suggests that offenders perpetrate such crimes to strengthen their own dominant social position while reinforcing the subordinate position of 'othered' groups. Her ideas of the punishment of identity performance and the 'policing' of boundaries are particularly instructive, and thus her notion of hate crime will be adopted and then debated within the context of the victimisation of goths, and it is to a discussion of the facets of this subculture that the article now turns.

\section{Goth Subculture}

Since its origination around thirty years ago the goth subculture has evolved, changed and above all endured, to become a 'way of life' for many goths that demands a 'considerable proportion' of their sense of self (P. Hodkinson, 2002). Yet when it emerged, as a spectacular youth culture in the post-punk era of the late 1970s and early 1980s, it appeared to be another manifestation of the multiplicity of such styles that have been a feature of the lives of young British people since at least the 1950s (P. Hodkinson and Deicke, 2007). From its beginning 
goth was distinctive and different, melding elements of punk and glam rock into a subculture that developed into an “'aesthetic,” a particular way of seeing and of being seen’ (Wilkins, 2004: 334). With an emphasis on the dark and the sinister, goths sported 'black eye make-up on pale grounding, black clothes with conspicuous cuts and fabrics, elaborate big hairdos, and melodramatic gestures’ (Brill, 2007: 113). The early goth scene revolved around bands such as Bauhaus, Siouxsie and the Banshees and then the Sisters of Mercy, The Fields of the Nephilim, The Mission and The Cure, whose doom-laden music attracted substantial audiences noted for their 'deathly pallor, backcombed or ratted black hair, ruffled Regency shirts, stovepipe hats, leather garments, spiked dog collars, the ensemble accessorised with religious, magical or macabre jewellery’ (Reynolds, 2005: 423). This visually stunning image made goths stand out from the norm, even in an era populated by a number of other ‘shocking’ subcultures.

Since the 1980s goth has developed and diversified, and now studies of the subculture encompass literature, art, films and fashion, as well as music and clothes (see Baddeley, 2006). A fascinating aspect of this evolution has been the prioritising of self-expression and the tolerance, and indeed encouragement, of minority sexual behaviour, whether this is homosexual, bisexual, polyamorous or inclined towards sado-masochism and fetishism (Wilkins, 2004; Brill, 2008). This open and broad-minded philosophy extends to gender performance, exemplified by its 'femininity and ambiguity', which, for P. Hodkinson (2002), is one of the subculture's most important features. Typified by the androgynous appearance of many males and the 'hyperfeminine' look of females ${ }^{2}$, goth venerates 'a particular, dark and mystical version of femininity for both sexes' which has seen 'make-up, jewellery, long hair and traditionally female modes of attire like skirts and tight fishnet tops [become] staples of goth style for males and females' (Brill, 2008: 113). For many goths, this acceptance of difference, coupled with their non-aggressive outlook, demarcates them from those in the mainstream, the 'trendies' or 'townies' viewed (perhaps rather stereotypically) as ignorant, intolerant and violent (Barker, 2003). P. Hodkinson (2005) notes that goths will draw these distinct boundaries themselves, deliberately setting themselves apart from those outside the 
subculture, thereby reinforcing the significant sense of collective affiliation between goths and their distance from 'conventional others'.

Although goth subculture enjoyed a peak of popularity in the mid-to-late 1980s it has nevertheless maintained a significant, if more underground, presence within broader popular culture ever since (Brill, 2007). It has demonstrated an ability to absorb other musical and fashion influences, such as punk, nu-metal, industrial, new romantic and indie, to evolve several different stylistic, but still clearly gothic, strands of its own (Barker, 2003). ${ }^{3}$ Its followers, typically middle-class, white and divided evenly between males and females (P. Hodkinson, 2002: 70), have created and sustained a scene that is unique, cohesive, tight-knit and proud of its difference, and one which balances expressions of individuality within a collective sense of shared cultural norms, in a similar fashion to other distinctive and longstanding subcultures such as punk (Worley, 2010). The contemporary scene includes specialist clothes shops, clubs, pubs and websites, and has, as a twice-yearly highlight, the 'Whitby Goth Weekender', held in the coastal Yorkshire town famously associated with the fictional arrival of the vampire Dracula in Bram Stoker's novel of the same name.

Thus, for P. Hodkinson (2002), being a goth involves high levels of commitment to the subculture to the extent that it can both reflect and dominate participants' identities and sense of self. Baddeley (2006: 7; 10) develops this point, suggesting that:

[Goth] is more than just a youth subculture, gloomy aesthetic or literary genre. It is a philosophical perspective - a view of the world ... It is the cosmos in negative, inverted - the strange and eerie are commonplace, while the everyday is somehow uncanny ... it is an aesthetic, a viewpoint, even a lifestyle, its tradition a legacy of subversion and shadow.

This would appear to indicate that goth is more than a mere fashion statement that young people might fleetingly adopt before moving on, and is instead, for many people, something more substantial and meaningful than that. For long-term adherents, it is their sense of 
distinctiveness and strong group identification that, arguably, allows them to consider themselves as an identifiable minority community similar to other minority communities that are classified as a hate crime victim groups. Similarly, it is their sense of separation, and their distinctive and challenging appearance, that makes goths an easily identifiable 'outgroup' that, like hate crime victim groups, is prone to harassment. Interestingly, though, Sophie Lancaster and Robert Maltby, whilst almost always wearing clothes and make-up clearly identifiable as 'goth', did not like to think of themselves as belonging to a rigid goth subculture (M. Hodkinson, 2008). However, their startling appearance caused them to be victimised on more than one occasion before the violent assault upon them in August 2007. This article will now discuss Sophie's murder in more detail before assessing the evidence of the victimisation of goths more generally.

\section{The Killing of Sophie Lancaster}

After spending the evening of 10 August 2007 at a friend's place in a different part of the town of Bacup, Lancashire, from where they lived, 21 year-old Robert Maltby and his partner Sophie Lancaster (20) decided to walk home, stopping off at an all-nigh petrol station on their way back (Court of Appeal, 2008). Whilst there they bumped into a group of local youths, with whom they chatted amicably, strolling with them to the skate-ramp area of the local Stubbylee Park. Then, referring to Maltby, one of the youths asked his friends: 'Shall we batter him?' before another youth ran across and, without provocation, punched Maltby in the face. This precipitated a sustained and violent assault upon the defenceless Maltby by five youths. The Court of Appeal described what followed:

[Maltby] was brought to the ground by punches and kicks. When on the ground he was kicked viciously to the head and body, and at least one of his assailants stamped on his head ... With remarkable courage Miss Lancaster rushed to give whatever assistance to him she could, and as he lay prone, she cradled her boyfriend's head in her lap, calling for help and shouting at the appellants to leave him alone. [Ryan] Herbert and [Brendan] Harris turned their attention to her and she, too, was subjected 
to a sustained and vicious attack which involved kicking and stamping until, she too in her turn, was beaten unconscious

(Court of Appeal, 2008: 3).

A horrified witness, a 15 year-old boy, later told police that Lancaster's assailants were 'running over and just kicking her in the head and jumping up and down on her head' and another bystander, a 14-year-old girl, said that she: 'started crying because I'd never seen anything like that. They were all just booting them. They were making loads of noises, screaming noises’' (Wainwright, 2008: 15).

A 999 made by an hysterical teenage witness, played to the court at the subsequent trial of the assailants, painted an horrific portrait of the scene: 'We need an ambulance at Bacup Park, this mosher's just been banged because he's a mosher ${ }^{4} \ldots$ It's a mosher just been banged for no reason. His girlfriend is on the floor as well. They're still breathing but they are full of blood. Please just send an ambulance quick. She’s choking on her blood ... it's all over their hands, all coming out of their eyes, all out their nose and everything. Please just help us quick, please, please’ (BBC News, 2008).

After departing the scene of the assault the attackers appeared to revel in what they had done, telling friends that they had 'done summat good', and that: 'There’s two moshers nearly dead up Bacup Park - you wanna see them - they're a right mess' (Wainwright, 2008: 15). A male witness said that they behaved 'in a giddy way, hyper-active and bouncing around doing silly things, it was as though they were boasting what they had done' (Court of Appeal, 2008: 3).

As paramedics arrived in Stubbylee Park they discovered Maltby and Lancaster lying together, unconscious and saturated with blood. Their injuries were so severe that the paramedics could not work out the sex of either (Wainwright, 2008). Both were rushed to hospital and placed in intensive care, where it was found that Maltby had 22 separate injuries, including multiple bruises, cuts and swellings; Lancaster had 17 similar sites. In both cases 
the principal target of assault had been their heads (Court of Appeal, 2008: 4). After a few days Maltby gradually began to recover, and was released from hospital on 24 August, although the damage inflicted upon his physical and mental health was long-term (Lancashire Telegraph, 2009). Lancaster, however, never regained consciousness and she died in her mother's arms on the same day Maltby left hospital (Court of Appeal, 2008: 4-5).

At the subsequent trial of the five assailants the judge, Anthony Russell QC, described the attack as: 'the worst case of causing grievous bodily harm with intent by kicking that I have come across in 30 years practice as a criminal barrister and in my career as a judge' (Court of Appeal, 2008: 11). Michael Shorrock, QC, for the prosecution, said that Maltby and Lancaster had been targeted 'not for anything they had said or done but because they dressed differently’ (Jenkins, 2008: 25). Judge Russell concurred, telling the defendants that:

I am satisfied that the only reason for this wholly unprovoked attack, was that Robert Maltby and Sophie Lancaster were singled out for their appearance alone because they looked and dressed differently from you and your friends. I regard this as a serious aggravating feature of this case, which is to be equated with other hate crimes such as those where people of different races, religions, or sexual orientation are attacked because they are different.

(Court of Appeal, 2008: 6)

It appeared that, for Judge Russell, the defining characteristic of a hate crime is that victims are targeted because of their difference, whatever this difference may be, thereby drawing distinction between his views and those of the likes of Perry (2009), discussed above, who view hate crimes as a mechanism by which powerful social groupings can oppress already marginalised minorities. Issues of hierarchy, dominance and power are, for Perry, a fundamental indicator of what differentiates hate crime from other forms of violence and harassment, but for Judge Russell the key consideration was that, as in the case of 
homophobic or racist assault, for example, the victims were targeted because they were different from the accepted norm. This is a fascinating aspect of this case, and will be explored further below.

At their trial Brendan Harris and Ryan Herbert, the two ringleaders of the violence, were convicted of the murder of Lancaster and given prison sentences of 18 and 16 years respectively. The other assailants, Daniel Mallett and brothers Joseph and Danny Hulme, were sentenced to between four and five years each for grievous bodily harm with intent upon Maltby. The case shocked and divided the residents of Bacup, their home town which sits in the Rossendale Valley, geographically remote, economically deprived and virtually monoethnic. ${ }^{5}$ Journalist Mark Hodkinson's investigation into the nature of Bacup found a town with a significant crime problem, characterised by a feelings of isolation, close-knit 'localism' and social conservatism, where those whose appearance is radically different noticeably stand out, whether they be goths, people from other alternative subcultures, or the small number of households from visible minority ethnic backgrounds. This hostility towards the 'other' characterises many such isolated and monocultural communities and can manifest itself in acts of abuse and violence against minority groups (Garland and Chakraborti, 2006). Indeed, Hodkinson found that minority ethnic families 'get firebombed out of their houses and given a whack with a baseball bat to make sure they get the message' to leave Bacup (M. Hodkinson, 2008: 31), and suggested that this fear of difference and enmity towards 'others' and 'outsiders' commonly manifested itself in the harassment of goths. The victimisation of Maltby and Lancaster was part of a wider pattern of such abuse.

At first glance, then, the assault upon Maltby and Lancaster appears to have some similarities with crimes commonly viewed and designated as 'hate crimes'. For example, the victims were part of a marginalised social 'outgroup' that is often the recipient of harassment: indeed, Maltby and Lancaster had been victimised on several previous occasions due to their appearance (Purdy, 2008), just as the harassment of members of racial and religious minorities (for example) can form, in many cases, part of an ongoing process of victimisation 
(Bowling, 1999). Also, Maltby and Lancaster were unknown to their attackers, meaning that the assault shared the 'stranger danger' aspect of recognised hate crimes (Saucier et al., 2006). In addition, while the use of excessive violence may not in itself be an indicator of whether an attack is viewed as a hate crime or not, the savagery of the attack upon Maltby and Lancaster was reminiscent of the extreme nature of violent homophobic hate crimes (Chakraborti and Garland, 2009). Furthermore, just as in other cases of hate crime, the surviving victim was left psychologically scarred and, furthermore, the incident impacted significantly upon the feelings of safety and security of the victims' wider community (in this case, goths (Purdy, 2008)). It is to a discussion of the nature and patterns of the targeted victimisation of goths that this article now turns.

\section{The Targeted Victimisation of Goths}

Following Sophie Lancaster's death, a number of goths and 'alternatives' began a campaign to get attacks against members of their subcultures recognised as hate crimes and included in wider hate crime legislation. Part of this campaign involved the gathering of around 7,100 signatures for an online petition supporting their views (Prime Minister's Office, 2008), a sizeable number which provides some evidence of widespread concern amongst goths and 'alternatives' that they are being targeted repeatedly because of their appearance and group membership. The wording of the petition, with its emphasis upon the victimisation of those 'who prefer "darker” fashions' (ibid), is indicative of the concern that it is specifically goths and 'alternatives', rather members of other subcultures (such as mods or casuals) whose fashions do not noticeably stand out from the norm, that are most at risk of attack. The advent of the 'Alternatives Have Rights Too' website ${ }^{6}$ (that offers a forum for victims of similar crimes to share their experiences), set up in response to the 'sustained torrent of abuse' heaped upon goths and 'alternatives' in the northern English town of Stockton, also indicates that this type of harassment may be commonplace (Richardson, 2008: 31). 
However, concrete evidence of the precise nature and frequency of the victimisation of goths is hard to come by, and, as it is such an under-researched topic, much of the evidence is impressionistic. Brill (2008: 123), for example, believes that goths 'regularly experience abuse for their style of dress and other cultural preferences', with verbal insults, such as 'Satan', 'witch' or 'corpse', directed at them. Barker (2003: 43) notes that all of the young goths she interviewed reported being recipients of verbal abuse 'that frequently became physical'. A spokesperson for the Stamp Out Prejudice, Hatred and Intolerance Everywhere campaign (S.O.P.H.I.E.) ${ }^{7}$, that was instigated after Sophie Lancaster's death, estimated that 70 per cent of those who had contacted the campaign had been victimised due to their alternative look (M. Hodkinson, 2008: 32) ${ }^{8}$. There is also plenty of anecdotal evidence to suggest that the problem is commonplace. Many of the Goths who participated in Paul Hodkinson's extensive research reported suffering 'prejudice and occasional violence' from members of the public, due to their 'unconventional appearance' (P. Hodkinson, 2002: 74). Goths interviewed by Purdy (2008) reflected this view, claiming that they were abused on a daily basis, especially by people acting in gangs. There is also an impression that such harassment is a nationwide issue, with Garland (2010) citing evidence of similar victimisation of goths in Plymouth in the West Country to that uncovered in Yorkshire in the north of England, as one Sheffield-based goth stated:

We live in a world that doesn't accept this kind of difference and young people are continuously mocked, attacked and sometimes even killed for the way they look ... There are hundreds of stories about the abuse suffered by our city's 'different' young people. We need to stop the prejudice.

(The Star (Sheffield), 2008).

A violent attack upon two 'emo' teenagers in Folkestone, Kent, in the south of England in 2009 also reflects the national nature of the problem. ${ }^{9}$ There is also some evidence that this assault formed part of a wider pattern of verbal and physical harassment suffered by emos, 
goths and 'alternatives' in the town (Denham, 2009). Assaults upon members of these subcultures are, though, much less frequent than verbal abuse, although the impact upon their victims and their wider subcultural communities is still significant. For example, a goth friend of Lancaster's recounted being threatened with a meat cleaver by a stranger whilst on a night out, and that his goth friends had also been spat at and punched (M. Hodkinson, 2008: 32). Almost a year after Lancaster's murder another similar assault occurred in Leeds, where Paul Gibbs, a 26 year-old goth, was the victim of a 'brutal and sustained gang attack' in a public park during which he was kicked, punched and stamped upon, causing him to lapse into a coma. His also had his ear sliced off while two teenage goths were hospitalised as a result of the same incident (Bullough, 2009). It was reported that, before the attack, one of the assailants told his friends: 'I'm a chav and I'm going to get some moshers' and other witnesses heard the three perpetrators screaming 'dirty moshers and goths' at their intended victims (Gardner, 2009). At their subsequent trial Judge James Spencer said, when sentencing the attackers to prison terms of between two and four-and-a-half years, that: 'It is difficult to describe the extent of the evil involved' (ibid).

The use of language by the attackers is also of interest here. The statement of selfidentification by one of the assailants as a 'chav' deliberately drew the line between the 'norm' of the attackers and the 'freakishness' of the outsider goths, thus justifying, in their eyes, the assault they were about to commit upon a demonised outgroup. The fact they also abused the goths for being 'dirty' also reflects a stereotype about them mentioned in other research (Muggleton, 2000), and the widely-held perception that that goths and emos are deemed 'passive' could also increase their chance of assault, as a goth spokesperson suggests:

Goth teenagers can tend to be bookish, quiet and thoughtful. As a result they can sometimes become distanced from the majority and become targeted. In my experience of over 20 years, as a general rule, you have to search hard to find a goth who is violent in nature and even harder still to find one who has not been targeted in some way. 
These packs so often see a slightly built guy on his own, wearing make-up and to them, he is fair game, an easy target to bully.

(cited in Purdy, 2008)

The role that the victim plays in their own victimisation, by inadvertently presenting themselves as a 'soft target' to a potential perpetrator, has been mooted by Fisher and Salfati (2009) as being an explanatory factor in the enactment of some hate crimes more broadly. Also drawing parallels between the victimisation of goths and recognised hate crimes, Brill (2008) notes that some of the harassment of goths can be homophobic in nature (even though its recipients are predominantly heterosexual). This abuse is especially directed at some male goths, whose androgynous and effeminate appearance can provoke 'frequent' homophobic insults or assault from members of the public. Some of Brill's male Goth interviewees, for instance, reported being called 'transvestite', 'poof', 'queer', 'batty boy' and 'fucking poofter' in the street (Brill, 2008: 50; 83), and she herself witnessed the homophobic abuse of male goths by football supporters (ibid). Some of those within the goth subculture feel that this places male goths at a higher risk of prejudiced victimisation than females, who, with their typically 'hyperfeminine' gothic appearance, instead tend to be recipients of sexual harassment. As Brill (2008: 51-52) argues:

For a straight man, adopting effeminacy with its attendant risk of homophobic abuse can be seen as a deliberate - and hence courageous - step towards the marginal position which women and gay men have in general society. For a woman, by contrast, at least the milder forms of sexual harassment are a fairly normal experience; they simply come with the territory of the inferior social position women have been assigned in our culture.

\section{Comparisons With Recognised Forms of Hate Crime}


From the available evidence detailed above it appears that the most common form of harassment of goths is verbal and that, more often than not, the perpetrators of anti-goth abuse are young males acting in gangs. This is similar to the pattern found for recognised forms of hate crime, such as racist or homophobic, in which victims also report frequent verbal victimisation, often from youths in groups (Levin et al., 2007; McDevitt et al., 2002).

There is also the suggestion that, like forms of recognised hate crime, verbal and physical assaults upon goths hurt more than ordinary crimes as they are an attack upon the victim's core identity. They also impact upon the victim's wider community, especially in the case of violent assaults, such as the attack upon Maltby and Lancaster that clearly was of concern to goths and alternatives nationwide (Purdy, 2008). There is some evidence, as P. Hodkinson (2002) argues, that such targeted violence can strengthen the victim's sense of subcultural identity as it can, in many cases, be seen as a 'right of passage' that goths go through as an inevitable part of being in that subculture. While this is not being disputed here, a distinction does need to be drawn between the strength of someone’s belief and emergence in a lifestyle, which may be bolstered by an experience of victimisation, and their inner sense of safety and security, which may be damaged as a result of the same incident.

It is also interesting that the two most shocking examples of violence discussed in this article (the assaults upon Lancaster and Gibbs) occurred in public parks in the home towns of the victims, where presumably they felt reasonably safe and yet were brutally victimised due to their 'difference'. Tying in with this, there is some evidence that, in the case of racist, religiously-motivated, homophobic and transphobic hate crime, it is in public spaces too that victims are most at risk (Chakraborti and Garland, 2009), whether this be town centres, parks or on public transport. ${ }^{10}$ Although, like the recognised forms of hate crime, violent assaults upon goths are rare, they act as 'signal' events to create the impression among sections of the 'alternative’ community that such attacks are frequent and may even be growing in number, increasing the fear of becoming a victim and enhancing feelings of insecurity (Denham, 2009). Paul Hodkinson (2002), for example, reports that many goths and 'alternatives' choose 
to avoid certain venues or areas of town and city centres where they feel they might be at a higher risk of harassment, just as gay or transgendered people also do in many instances (Dick, 2008).

The targeted victimisation of goths is commonly perpetrated by 'ordinary' members of the public who do not know their targets personally. They are therefore 'stranger danger' crimes in a similar fashion to recognised hate crimes in which perpetrators' prejudice against identifiable outgroups, such as transgendered people or homosexuals, can spill over into verbal abuse or violence. Such groups may end up being punished for 'crossing the line', as Perry (2009: 70-71) argues:

... not everyone always performs "appropriately”. Frequently, we construct our gender, or race, or sexuality in ways that in fact challenge or threaten sociocultural arrangements. We step out of line, cross sacred boundaries, forget our place ... The tensions between dominant and subordinate actors may culminate in violent efforts to reassert the dominance of the former and realign the position of the latter.

The attackers in the Bacup case - whose behaviour was described as 'very aggressive, intolerant and callous and violent' by the original trial judge (Court of Appeal, 2008: 6) appeared to be punishing Lancaster and Maltby for their deviant identity performance. It was as if they found the appearance of the couple intimidating or challenging, just as a number of the gothic research subjects in Brill's (2008) study felt that their fashions were 'threatening' to the public. The behaviour of the Bacup assailants was in many ways mirrored by those involved in the Leeds attack, whose language during the incident ('dirty moshers and goths') betrayed their own bigotry, small-mindedness and fear of the other.

Such attacks on members of youth subcultures are not new, of course - Savage (1991), for example, refers to the frequency with which punks were assaulted by 'ordinary' members of the public in the mid-1970s - but the anecdotal evidence summarised here may suggest that assaults against goths may be more frequent than those against members of other, less 
conspicuous or more accepted subcultures. While a degree of caution needs to be noted with the drawing of strong conclusions from such anecdotal evidence, this apparent higher risk of victimisation is something that goths share with established hate crime victim groups, and indeed this may well be only one of a number of characteristics that link attacks upon goths with those that are classified as hate crimes. The final section of this article will now assess the difficulties of categorising such anti-goth harassment as a hate crime.

\section{Conclusion: Away From Structural Notions of Hate Crime?}

The murder of Sophie Lancaster undoubtedly sent shockwaves through the goth and alternative communities, partly due to its brutal nature and partly because, as the judge in the original trial of the Bacup attackers stated, she was targeted because of her distinctive appearance. For Judge Russell, this was a 'serious aggravating feature' which should 'be equated with other hate crimes such as those where people of different races, religions, or sexual orientation are attacked because they are different' (Court of Appeal, 2008: 5) ${ }^{11}$ This statement is integral to the discussions of the nature of anti-goth victimisation and its similarity to recognised hate crimes that this article has debated. It began by examining the characteristics of goth subculture, including the 'challenging' fashions, make-up and hairstyles worn by many adherents, the androgynous dress of males and the relatively isolated but close-knit nature of the contemporary goth scene.

The article then discussed the assault upon Robert Maltby and Sophie Lancaster that resulted in the hospitalisation of the former and the death of the latter, and saw that its apparent motivation was fear and loathing, on behalf of the attackers, of their gothic and alternative appearance. There was also evidence that this incident was part of a broader pattern of the harassment and abuse of goths in that town of Bacup and that Maltby and Lancaster had previously been victimised there.

The article then examined evidence of the broader targeting of goths, which appeared to indicate that the most common form of harassment is verbal and that single incidents tend to 
be part of a long-term pattern of victimisation, again revealing similarities with hate crimes more generally. Some of the physical violence has been executed with a ferocity reminiscent of the merciless homophobic assault upon Jody Dobrowski in 2005 that was prosecuted as a hate crime. Intriguingly, it was also suggested that some of the victimisation of male goths is homophobic in nature as they are targeted because of their gender-ambiguous appearance (Brill, 2008).

Also, according to Perry (2001) sections of society attach negative, oppositional traits to each of the hate crime 'outgroups'. Again, it could be that this applies to goths, who are seen as a freakish and deviant outsider group by some, in contrast to the 'normal' behaviour and dress of mainstream society. Their presence can be unsettling and threatening, especially those in monocultural, socially conservative and isolated communities like Bacup, hidden as it is in the Rossendale Valley.

However, despite these similarities, it is very difficult to decide which groups should be included under the hate crime 'umbrella' and which should not. For Perry (2001: 10), hate crimes are 'directed towards already stigmatised and marginalised groups', tying in with the idea, discussed earlier, that the concept of hate crime has its roots in the civil rights struggles in the US of forty or so years ago, as it was seen as a way of underlying the commonalities (such as deprivation, discrimination and victimisation) shared in the lives of the campaigning groups.

If this idea is accepted, then it may be that the inclusion of subcultural groups such as goths may not only broaden the notion of hate crime too far for it to remain meaningful (see Jacobs and Potter, 1998), but it may also trivialise or belittle the history of marginalisation of recognised minority hate crime groups and their experiences as victims of harassment and violence. As a number of authors have found (Brill, 2008, Barker, 2004 or P. Hodkinson, 2002), goths tend to be white and middle-class, often well-educated or in professional jobs. This profile hardly fits that of those communities, such as African Americans in the States, 
whose history of oppression, victimisation and struggle for equality makes any comparison with the experience of goths seem trite and rather trivial.

Similarly, it could be argued that the parameters of inclusion under the hate crime 'umbrella' should be set fairly narrowly, to include only those groups that are targeted because of their intrinsic characteristics, such as their ethnicity or disability, which they are either born with or cannot alter. Although their subcultural membership may be central to their sense of identity and lifestyle, goths, by contrast, are not, of course, born into the subculture and thus choose to participate in its activities. Their adopted literature, clothes, hairstyles and music, while reflecting their own tastes and indeed personalities, are just that adopted - and this significant difference between subcultural victim groups, and minority community victim groups, needs to be acknowledged in this discussion.

However, while it is accepted here that those in alternative or gothic subcultures are not born that way nor are part of a community that has a longstanding history of civil rights campaigns, it is nevertheless suggested that for many goths their subculture is a central and vital part of their lives. Being a goth governs not just their leisure time but also their everyday activities, and is something that, far from being an ephemeral fad, becomes a fixture in their lives for decades (P. Hodkinson, 2005; Baddeley, 2006). It involves high levels of long-term commitment that generates a sense of solidarity and community with other goths. Attacks against goths, and especially the high-profile killing of Sophie Lancaster, therefore do impact on their wider community and can therefore 'hurt more', just as hate crimes, such as the murders of Anthony Walker or Brent Martin, also do. This issue highlights just how problematic and contentious the process of framing the boundaries of hate crime can be.

However, as discussed earlier, Perry (2009: 72) asserts that 'hate-motivated violence is used to sustain the privilege of the dominant group and to police the boundaries of the group by reminding the other of his or her place'. It is less clear that the victimisation of goths fits into this structural idea of hate crime that sees powerful social groups perpetrating hate acts against deprived 'outgroups' in order to keep them in their social station. Instead, it appears 
that it is the fear of difference, and of the despised 'other', that drives much of the anti-goth harassment, and therefore it could be argued that Perry's structural view of hate crimes masks their most fundamental aspect, which is that the victim is targeted solely because of their group affiliation (Gerstenfeld, 2004). In other words, it is the fact that victims are targeted because of who they are that is the most important facet of such incidents, as it is their membership of a despised social outgroup that sparks abuse and assaults against them. Such harassment is therefore less to do with keeping the victim in their subordinate place within the social structure and more to do with being motivated by a more base and unthinking instinct: the fear or hatred of difference.

It could also be argued, though, that the most important aspect of victimisation is the pain, suffering and fear that it causes to the victim and their wider community: something that was very evident in the aftermath of the Lancaster case and seems to be an ever-present facet of life as a goth or 'alternative'. To be targeted due to one's difference, in whatever form this may take, and the fear this may cause, could well be the most important aspects of these discussions. If this is the case, then Judge Russell's understanding of Sophie Lancaster's murder as a hate crime may have been more prescient and foresighted than it appeared at first sight. It may therefore be time to reject structural notions of hate crime that overplay the importance of social hierarchies and the subordinate position of the victim within them, and instead widen the parameters of the concept of hate crime to include victims of targeted violence whatever their social status or background.

\section{References}

Baddeley, G. (2006). Goth Chic: A Connoisseur's Guide to Dark Culture. $2^{\text {nd }}$ edition, Plexus Publishing; London.

Barker, M. (2003). Satanic Subcultures? A Discourse Analysis of the Self-Perceptions of Young Goths and Pagans' in Cultural Expressions of Evil and Wickedness: Wrath, Sex, Crime (T. Waddell, ed.) pp. 37-57. Editions Rodopi BV; Amsterdam. 
BBC News (2008). Attack Jury Played Desperate Call. BBC News website at http://news.bbc.co.uk/go/pr/fr/-/1/hi/england/lancashire/7292869.stm, 12 March.

Bennett, S., Nolan, J.J. and Conti, N. (2009). Defining and Measuring Hate Crime: A Potpourri of Issues. In Hate Crimes Volume 1: Understanding and Defining Hate Crime (B. Levin ed.) pp. 163-182. Praeger; Westport.

Bowling, B. (1999). Violent Racism: Victimisation, Policing and Social Context. Oxford University Press; Oxford.

Brill, D. (2008). Goth Culture: Gender, Sexuality and Style. Berg; Oxford.

Brill, D. (2007). Gender, Status and Subcultural Capital in the Goth Scene. In Youth Cultures: Scenes, Subcultures and Tribes (P. Hodkinson and W. Deicke eds) pp. 111-126. Routledge; London.

Bullough, C. (2009). Gang Jailed for Barbaric Attack on Rothwell Goth; Goth Had His Ear Sliced Off. Wakefield Express, 5 June.

Chakraborti, N. and Garland, J. (2009). Hate Crime: Impact, Causes and Responses. Sage; London.

Court of Appeal (2008). Judgment: Before The Lord Chief Justice Mr Justice Owen and Mr Justice Christopher Clarke Between: R v Herbert (1), Harris (2), Joseph Hulme (3), Danny Hulme (4), and Daniel Mallett (5), Royal Courts of Justice; London EWCA Crim 2501.

Denham, C. (2009). Don’t Abuse Us Because of the Way We Look. Kentish Express, 7 April.

Fisher, C. and Salfati, C.G. (2009). Behavior or Motivation: Typology of Hate-Motivated Offenders. In Hate Crimes Volume 4: Hate Crime Offenders (R. Blazak ed.) pp. 103-136. Praeger; Westport.

Gardner, T. (2009). Rothwell Park Attack Goth Victim Interview. Rothwell Today, 9 June, http://www.rothwelltoday.co.uk/news/Rothwell-park-attack-Goth-victim.5348497.jp

Gardner, T. (2009). Rothwell: Man’s Ear Sliced Off in Thugs’ Rampage. Rothwell Today, 8 June, http://www.rothwelltoday.co.uk/news/Rothwell-Man39s-ear-sliced-off.5344242.jp 
Garland, J. (2010). The Victimisation of Goths and the Boundaries of Hate Crime. In Hate Crime: Concepts, Policy, Future Directions (N. Chakraborti ed.) pp. 40-57. Willan; Cullompton.

Garland, J. and Chakraborti, N. (2006). Recognising and Responding to Victims of Rural Racism. International Review of Victimology. 13 (1): 49-69.

Garland, J. and Chakraborti, N. (2004). England's Green and Pleasant Land? Examining Racist Prejudice in a Rural Context. Patterns of Prejudice. 38 (4): 383-398.

Gerstenfeld, P.B. (2004). Hate Crimes: Causes, Controls and Controversies, Sage; London.

Grattet, R. and Jenness, V. (2003). The Birth and Maturation of Hate Crime Policy in the United States. In Hate and Bias Crime: A Reader (B. Perry ed.) pp. 389-408. Routledge; London.

Hodkinson, M. (2008). On 11 August 2007 a Young Goth Died at the Hands of a Brutal Teenage Gang: One Year On, Thousands of Her Supporters the World Over Have United in the Name of Tolerance - and the Girl Who Dared to be Different. Observer Magazine, 3 August, pp. 28-34.

Hodkinson, P. (2005). Insider Research in the Study of Youth Cultures. Journal of Youth Studies, 8 (2): 131-149.

Hodkinson, P. (2002). Goth: Identity, Style and Subculture, Berg; Oxford.

Hodkinson, P. and Deicke, W. (eds) (2007). Youth Cultures: Scenes, Subcultures and Tribes. Routledge; London.

Hopkins, N. and Hall, S. (2000). The Nail Bomber: Festering Hate That Turned Quiet Son into a Murderer. Guardian, 1 July, p. 2.

Iganski, P. (2008). 'Hate Crime’ and the City, The Policy Press; Bristol.

Jacobs, J. and Potter, K. (1998). Hate Crimes: Criminal Law and Identity Politics, Oxford University Press; Oxford.

Jenkins, R. (2008). Boy of 15 Who Attacked Woman For Being a Goth Is Convicted of Murder. The Times, 28 March, p. 25. 
Lancashire Telegraph (2009). Sophie Lancaster's Mum to Meet Top MP. Lancashire Telegraph, 20 January.

Levin, J., Rabrenovic, G., Ferraro, V., Doran, T. and Methe, D. (2007). When a Crime Committed by a Teenager Becomes a Hate Crime: Results From Two Studies. American Behavioral Scientist, 51 (2): 246-257.

McDevitt, J., Levin, J. and Bennett, S. (2002). Hate Crime Offenders: An Expanded Typology. Journal of Social Issues. 58 (2): 303-317.

McLagan, G. and Lowles, N. (2000). Mr. Bad: The Secret Life of Racist Bomber and Killer David Copeland. John Blake Publishing; London.

Muggleton, D. (2000). Inside Subculture: The Postmodern Meaning of Style. Berg; Oxford.

Office for National Statistics (2005). Census 2001: the Most Comprehensive Survey of the UK Population, at http://www.statistics.gov.uk/census2001/census2001.asp.

Perry, B. (2009). The Sociology of Hate: Theoretical Approaches. In Hate Crimes Volume 1: Understanding and Defining Hate Crime (B. Levin ed.) pp. 55-76. Praeger; Westport.

Perry, B. (2001). In the Name of Hate: Understanding Hate Crimes. Routledge; London.

Purdy, C. (2008). The Darker Side of Life as a Goth. BBC News website at http://news.bbc.co.uk/go/pr/fr/-/1/hi/england/lancashire/7314306.stm, 27 April.

Reynolds, S. (2005). Rip It Up and Start Again: Post-punk 1978-84. Faber and Faber Limited; London.

Richardson, L. (2008). Youth Forum Aims To End Hate Crimes. The Northern Echo, 29 September, p. 31.

Rowe, M. (2007). Introduction: Policing and Racism in the Limelight - the Politics and Context of the Lawrence Report, in Policing Beyond Macpherson: Issues in Policing, Race and Society (M. Rowe, ed.) pp. xi-xxiv. Willan; Cullompton.

Saucier, D.A., Brown, T.L., Mitchell, R.C. and Cawman, A.J. (2006). Effects of Victims' Characteristics on Attitudes Toward Hate Crimes. Journal of Interpersonal Violence, 21 (7): 890-909. 
Stamp Out Hatred and Intolerance Everywhere (S.O.P.H.I.E.). MySpace site at http://www.myspace.com/inmemoryofsophie

The Star (Sheffield) (2008). Goths to March Through Sheffield in Bid to Stop Abuse. The Star, July 18.

Wainwright, M. (2008). Woman Died After Drunken Gang Attacked Couple Dressed as Goths. Guardian, 13 March, p. 15.

Watkinson, D. (2009). Sophie Lancaster's Mum Set to Win Tougher Sentences for Hate Crimes. Lancashire Telegraph, 7 May.

Wilkins, A.C. (2004). "So Full Of Myself as a Chick”: Goth Women, Sexual Independence, and Gender Egalitarianism. Gender and Society, 18 (3): 328-349.

Worley, M. (2010). One Nation Under the Bomb: The Cold War and British Punk to 1984. Journal for the Study of Radicalism, forthcoming.

1 In this case, 'alternative' subcultures are considered to be those involving individuals with 'extreme' appearances, including spiked or vividly dyed hair, visible tattoos and multiple bodypiercings, and clothes, such as those worn by goths, which are considered to be outside of regular high street fashions.

2 Goth subcultural notions of male and female appearance and performance are characterised by this somewhat contradictory attitude, with androgyny desired in males but 'traditional criteria of feminine attractiveness' preferred in females (Brill, 2007: 118).

3 Baddeley (2006) notes that Goth clubs now play a variety of musical styles, ranging from traditional goth bands such as the Sisters of Mercy, through industrial acts such as Nine Inch Nails to more mainstream but 'dark' electronic acts like Gary Numan and Depeche Mode.

4 'Mosher' is a different term for a goth or a rock fan of 'alternative' appearance.

5 At the time of the most recent census Bacup had a population of 12,763 (Office for National Statistics, 2005). The town has its own 'traditional' dance troupe, the Coconutters (www.coconutters.co.uk), one of the very few such troupes left in England that deems it acceptable to blacken the faces of its dancers, in a similar fashion to the much criticised 'Darkie Day' celebrations in Padstow, Cornwall (see Garland and Chakraborti, 2004).

6 In 2010 the 'Alternatives Have Rights Too' website became 'The Only Alternative' social networking site for anyone considering themselves 'punk, rock, metal, hardcore, oi, goth, emo, rockabilly or any other kind of unconventional' at http://www.only-alternative.com/.

7 The main initial aims of the S.O.P.H.I.E. campaign were to promote tolerance of difference and change hate crime law to include those of alternative appearance as a victim group. Prior to the trial of Lancaster's killers it had been campaigning for her murder to be recognised as a hate crime.

8 The campaign has now become a charity, the Sophie Lancaster Foundation - see http://www.sophielancasterfoundation.com/.

9 The emo subculture is a relatively recent subcultural development, with adherents to its style often sporting dark clothes, hair and accessories that reflect its roots in goth subculture.

10 Quarmby (2008) cautions that disablist hate crime may be different in this regard. 
11 There is a suggestion that sentencing guidelines to judges in cases like these may be altered, to encourage them in future to impose longer sentences upon those found guilty of similar acts (Watkinson, 2009). 